necessitating plugging of the posterior nares, which after some time controlled the bleeding. Another examination of the blood, made a few days later, showed 580,000 red cells, 60,000 white, mainly lymphocytes hæmoglobin 15 per cent. On December and a little more tlian one week after admission, the patient appeared much better, and a more accurate examination of the blood revealed the following results: On a large number of slides $r, 500$ leucocytes were noted, and the percentages of the different varieties were found to be as follows: Lymphocytes, 76 per cent. ; polynuclear neutrophiles, r9.5 per cent.; large mononuclears, 1.8 per cent.; transitional forms, 23 per cent.; eosinophiles, 0.35 per cent Considerable difficulty was experienced in making an accurate estimate, inasmuch as very many small, dark, round bodies presented, resembling both in size and staining reactions the nuclei of red cells, free in the circulation; and, on the other hand, while the majority of lymphocytes would show a small zone of protoplasm around their nucleus : in others, again, while the nucleus itself was less deeply stained than that of the red cells, there was yet no evidence of a cell body. All such which were in any way dubious as being either lymphocytes or escaped nuclei were not taken into consideration in the estimate.

Many nucleated red cells were seen, mostly normoblasts, with a few megaloblasts. There was a marked poikilocytosis. The general blood count gave the following result: Red eells. 1,595,000; white cells, I7,300; that is to say, a ratio of $\mathrm{I}$ white to 94 cells. For several days subsequently there was marked general improvement, and the blood count showed $2,030,000$ red cells. 34,000 leucocytes, hæmoglobin 42 per cent. On December 20 th the patient, who had for the previous couple of days seemed weaker, manifested some new symptoms. Two rapidly-growing subcutaneous nodules appeared on the forehead, one of them being distinctly tender, and bleeding from the nose again ensued, necessitating plugging.

For the next three days the patient became distinctly worse; severe epistaxis continued, which was barely controlled with the greatest difficulty. The dulness over the sternum increased in size and intensity, larger nodules could be felt in the region of the retroperitoneal glands about the abdominal aorta, and in general the patient's whole condition was that of one moribund. Cultures from the blood were taken, but remained sterile. Examination of the blood on this, the last day of his life, showed a very much more marked leucocytosis, the lymphocytes being almost in excess of the red blood cells. Throughout the, whole course of his stay in the hospital the temperature had assumed an irregular intermittent type. The patient died on December ${ }_{23} \mathrm{rd}$, less than nine weeks from the onset of his illness.

The case, then, as observed, is of interest in more than one particular: in the first place as illustrating the difficulties of diagnosis between leukæmia and Hodgkin's disease. With a leucocytosis, which varies from a proportion of 1 to 75 up to 1 to 120 , or even more, it will seem scarcely justifiable to make an absolute diagnosis of lymphatic leukæmia, particularly, when we know that occasionally the blood in Hodgkin's disease may assume exactly that icondition, the leucocytosis being of the lymphocytic variety. Myelocytes were not present. The presence of numerous nucleated red cells will to many suggest the diagnosis of leukæmia although such a condition might occur in the most varied forms of disease which produce hæmolysis. Among other points that may be of interest in connection with this case is the mode of onset, which corresponds with that described by Hinterberger ${ }^{18}$ and others as showing the essential nature of such processes. In collecting together a large number of cases note has been taken of the large number of instarces of acute lymphomatous affections where the onset has followed upon some affection of the alimentary tract, such as stomatitis or ulcerative enteritis or similar conditions, all leading to the suspicion that the disease has risen through the entrance of some toxic or infective agent by way of the alimentary canal. As will be seen from the history of our present case, the symptoms followed directly upon an acute and painful affection of the lips and gums.

Whether or not, then, finally, we are justified in recognising in leucocytosis any special type of disease, our knowledge does not at present permit us to decide; but when we consider the difficulty with which author after author endeavours to satisfactorily classify and separate these different affections, it may not for the present seem unreasonable to still maintain under one group all these various forms-the leukæmias in their various manifestations, acute and chronic, lymphatic splenic, and myelogenous, the similar varieties of Hodgkin's disease, and all such like affections characterised by a hyperplasia of the lymph glandular structures where no primary focus of disease can be found to account for such a condition.

It merely remains for us to record our indebtedness to Professor James Stewart, in whose clinic the patients were observed, and by whose kind permission the material was placed at our disposal.

Since presenting the above paper before the Canada Medical Association, one of us (C. F. M.) had the opporturity of observing an $l$ treating a patient in whom the s: mptoms were so snggestive of the intimate relationship between leukæmia and pseudoleukæmia, that it seemed to us well worthy of mention in this article. A full report of the case has recently been published in the Montreal Medical Journal by Drs. Robins and Argue, resident physicians of the Royal Victoria Hospital.

The patient was a young Canadian, aged 19, and was sent to the Royal Victoria Hospital on August 6th by Dr. A. E. Vipond. For two weeks previously he had been suffering periodically from epistaxis, high irregular fever, progressive asthenia and pallor. There was general glandular enlargement, and his blood condition remained normal, so far as the leucocytes were concerned; in other words, the symptoms pointed definitely to acute Hodgkin's disease.

The blood examination on his admission revealed $3,166,000$ red cells, 8,000 white, and 42 per cent. of hæmoglobin. For the first two weeks after lis sojourn in the hospital his general condition improved, the leucocytes were not markedly increased at any time, nor were there any other notable changes. Suddenly, howtver, on the fifteenth day after entry, there was a marked change, with increased fever, recurrent hæmorrhages from the nose, and the blood examination within two days showed over 60,000 white cells to the c.mm. This leucocytosis persisted for a week, his condition otherwise getting progressively and rapidly worse. Life was prolonged for but one week more, and during that period the leucocytes again diminished in number, returning in about two days to normal, and on the day previous to death an estimate showed merely $14, \mathrm{coo}$ to the c.mm. It was observed, too, that the uric acid increase in the urine was coincident with the subsiding leucocytosis.

In the illness then, which lasted in all about six weeks, there was a period where undoubtedly all the typical signs of acute leukæmia were present, while on other occasions the examination revealed the usual classical symptoms of acute Hodgkin's disease. Nor is this merely a sequence of a leukæmia upon that of Hodgkin's disease, inasmuch as later the symptomatology had returned again to that of the original malady.

1 Virchow's Archiv, vol. cxxxvii, 1894. 2 Berlin. klin. Wochenschr., 1878. 3 Deutsch. Archiv für klin. Medicin, vol. xliv, 1889. 4 Specielle Pathologie und Therapie, 189r. 5 Zeitschr. für klin. Medicin, vol. Xxviii, 1896. 6 Virchow's Archiv, vol. exviii, 1890. 7 Deutsch Archiv für klin. Medicin, April, 1892. 8 Deutsch. med. Wochenschr., April, 1892.99 Ibid. September, 1892. 10 Practice of Medicine, 1886. 11 Montreal Medical Journal, 1894. 12 Rerlin. klin. Wochcnschr., 1877. 13 Wiener med. Blätter, 1886, ix. 14 Practice of Medicine, 1894. 15 Deutsch. Archiv fuir klin. Medicin, xxvi, 1879. 17 Journal of Pilysioloay, May, 1896. 18 Deutsch. Archiv für klin. Medicin, Bd. xlviii, 1891 .

\section{THE TREATMENT OF SYPHILIS BY INTRAVENOUS INJECTIONS OF MERCURY.}

By J. ERNEST LANE, F.R.C.S.,

Surgeon to Out-patients and Lecturer on Anatomy, St. Mary's Hospital ; Surgeon to the London Lock Hospital.

THE plan of treating syphilis by intravenous injections of mercurial solutions was originally suggested by Baccelli in I893, and has since been carried out by many Continental surgeons : in Italy by Jemma, Colombini, Nieddu, Campana, and Bruni ; in Germany by Görl, Neumann, and Lewin ; in France by Abadie; and in Russia by Stoukovenkoff and Kusel.

Having charge of all the male wards at the only hospital in London devoted to the treatment of venereal diseases, I have unusual opportunities of giving a fair and impartial trial to any novel method of treatment; and, with a view of estimating the value of this plan, I have systematically adopted it in every case of syphilis which has come under my care in the London Lock Hospital during the last nine months, and I can state with conviction that I have formed a very favourable opinion as to its merits, and believe that, with certain reservations, it compares favourably with other methods of treatment, whether it be by inunction, by intramuscular injection, or by internal medication, its special feature being the rapidity with which patients can be brought under the influence of mercury.

The preparation I have utilised throughout has been 
cyanide of mercury in I per cent. solution, and the amount used at each injection was usually 20 minims, or about $1 \frac{1}{4}$ gramme, though in some of the more severe cases I commenced with double this dose for the first one or two injections. At first the injections were employed every other dav, but after a short time I decided to introduce them daily. A loop of bandage is first tightly applied round the upper arm, and selection is made of the most prominent vein in the neighbourhood of the elbow-joint; the skin in that region is rendered aseptic in the customary manner, and the needle is thrust into the vein, the syringe filled with the solution being attached to it; the bandage is then removed, and the syringe is emptied into the vein and then rapidly withdrawn; the finger is placed on the puncture for a few seconds, and the operation is complete.

As will be pointed out later, when dealing with the advantages of this system, it is absolutely painless, and with ordinary precautions perfectly devoid of danger.

The number of cases treated amounted to 76 , and the number of injections made was upwards of 1,000 . I need hardly say that I personally did not administer all these injections ; they were carried out by my house-surgeons (Dr. Byles and Mr. Chopping), to whose care and skill I am indebted for the favourable results obtained. The case treated covered a very wide field, and embraced nearly all the possible manifestations of the disease, from the simple and uncomplicated case to severe tertiary ulcerative lesions of skin and mucous membranes, malignant syphilis, condylomata, iritis, and chronic and relapsing syphilides. The number of injections necessary varied from 46 to 4 .

As a result of the treatment, fifty patients were relieved, and by relieved I mean that they left the hospital absolutely free from syphilitic manifestations; sixteen improved under treatment, but still presented some traces of disease on their departure; four either refused to undergo the treatment, or had to be discharged from the hospital for misconduct, and in six instances the treatment had to be suspended owing to the impossibility of bringing the veins into sufficient prominence to allow of the injections entering them with any certainty, but in several of these cases great improvement was noted before the treatment was discontinued. It is a perfectly easy matter to determine if the injection has missed the vein by the pain, swelling, and bruising which shortly supervene, whereas the injections if properly effected are followed by no discomfort of any kind ; moreover, the sensation produced by the needle moving freely within the lumen of the vein differs widely from that which is imparted should it only have entered the cellular tissue. As a rule, very little inconvenience was experienced by those patients in whom the injections missed the vein, but in a case in which the injections were made into the dorsal veins of the foot, which were somewhat varicose, a skin slough shortly supervened, leaving an ulcer which resisted treatment for some time. The vein usually selected was the median basilic, and no appreciable change could be detected in its walls, though in one case as many as twenty-three injections were introduced into each arm. As previously stated, the patients submitted to this treatment were all of them males, and it is hardly necessary to point out that, in dealing with women, greater difficulties would be encountered owing to the smaller size of their veins.

All of the patients under my treatment were admitted into the wards of the hospital ; still I see no objection to the treatment being carried out in the out-patient departments. There was no selection of suitable cases, but every syphilitic patient who presented himself was submitted to the intravenous injections, whatever his bodily state, and a considerable proportion had resisted previous treatment in the out-patient department, and were transferred to the wards of the hospital in consequence; many of them were in a most unfavourable condition, being broken down by exposure, intemperance, and privations; nor were the patients very amenable to hospital discipline, and several of them left while still manifesting active signs of disease, whilst others had to be dismissed owing to breaches of regulations. In every case the diagnosis was made absolutely certain by the appearance of some secondary manifestation, and the treatment was never commenced until the nature of the case was satisfactorily proved. In a few cases diarrhœa supervened during the treatment, but these attacks were transitory, and were possibly due to other causes; in some instances gingivitis occurred, but it was not so marked as after other methods of mercurial administration, and in no case was salivation noticed; the hygiene of the mouth was carefully attended to. and alum gargles were emplozed two or three times a day. In a few instances polyuria and very slight albuminuria were observed after the first or second injections, but these soon disappeared and did not necessitate any modification in the treatment; the only other remarkable feature to be recorded is that many of the patients experienced a metallic taste in the mouth immediately after receiving the first few injections.

From the tabulated list I have extracted a few of the more severe cases as illustrating the effect of this treatment :

Case $x$ was that of an extensive and relapsing rupial eruption in a man. aged 22, who had been in the hospital under treatment by inunctions and iodides for upwards of three months. Under this treatment the symptoms cleared up temporarily, but after a month a relapse took place, and the rupial ulcers reappeared. In the course of the next three months forty-six injections were administered, and at the end of that period no trace of disease remained.

Case 5 was one of a serpiginous tertiary syphilide over a large surface of the trunk and chronic superficial glossitis. After nine injections the syphilide had disappeared, and the condition of the tongue was much improved.

Case 22 was a patient with tertiary ulceration of the glans penis of six months' duration, which had resisted all ordinary methods of treatment. After five injections the ulceration had completely healed.

Case 3 was a phaged nic sore of the prepuce accompanicd by a macular gyphilide. Two injections were given in the course of a week, at the end of which period the patient left the hospital with the sore healed, but with the syphilide still present.

Case 38 was a digital chancre of three months' duration, together with a general papulo-squamous syphilide and condylomata ani. All the symptoms cleared up after eight injections.

Case 47 was one of malignant syphilis; an indurated sore contracted five months previously was followed by rupial ulcers of scalp and limbs and superficial glossitis. After twenty-eight injections all symptoms had disappeared, the rupial ulcers taking only a fortnight in healing.

Case 57 was a patient who had contracted syphilis in India, and who was suffering from a tubercular syphilide of the arms. destructive ulceration of the alæ of the nose, ulceration of forehead, and who moreover, had been under treatment since the contraction of the disease. After thirty injections lhis symptoms had almost disappeared, but his impr thirty injections his symptoms had almost deposidering that syphilis contracted in the tropics is usually a most intractable disease.

The advantages of intravenous injections may be summarised as follows: They are absolutely painless, in which respect they are in direct contrast with intramuscular injections; the functions of the digestive tract are not interfered with; the doses of the mercurial salt are small, are certain of absorption, and can be easily regulated to the varying susceptibilities of different individuals; with ordinary precautions the treatment is perfectly safe, and, even if the vein is missed, little or no inconvenience is caused thereby ; the resulting improvement is certain and rapid, and consequently it would seem to be indicated in cases of cerebral syphilis; my experience does not warrant me in offering an opinion as to whether this treatment is followed by relapses, but so far I have not met with any. The only real objection I can see to the method is the difficulty experienced in some instances of bringing the veins into sufficient prominence, and in a certain proportion of cases, especially amongst women, this is an insuperable obstacle. In conclusion, I am of opinion that in intravenous injections we have a valuable addition to our antisyphilitic therapeutical agents, though the plan is one which obviously cannot be recommended as a routine in practice.

\section{SAFEGUARDS IN CHLOROFORM ADMINIS- TRATION.}

By W. J. J. ARNOLD, B.A., M.B., Cottage Hospital, Aberdare.

THE capital fault in the ordinary method of giving chloroform is the absolute want of control on the part of the administrator over the quantity that the patient may inhale with each inspiration. It is common to find a great variation in the depth of the respirations taken by the patient during the time that he is going under, and whilst respiration is more or less within his own control, a number of very shallow inspirations being followed quickly by several very deep inspirations, whereby he may inhale a quantity sufficient to paralyse his respiratory centre. I believe that this is the explanation of most of the deaths which occur before the patient has ever 